\title{
Thermomechanical Characterisation of Compressed Clay Bricks Reinforced by Thatch Fibres for the Optimal Use in Building
}

\author{
Madeleine Nitcheu1,2*, Pierre Meukam³ ${ }^{3}$ Jean Claude Damfeu ${ }^{3}$, Donatien Njomo ${ }^{1}$ \\ ${ }^{1}$ Department of Physics, Faculty of Science, Environmental Energy Technologies Laboratory (EETL), University of Yaounde I, \\ Yaounde, Cameroon \\ ${ }^{2}$ Department of Basic Scientific Teaching, School of Geology and Mining Engineering, University of Ngaoundere, Ngaoundere, \\ Cameroon \\ ${ }^{3}$ Laboratory of Energy, Water and Environment (L3E), National Advanced School of Engineering, Yaounde, Cameroon \\ Email: *mnietzche2@gmail.com
}

How to cite this paper: Nitcheu, M. Meukam, P., Damfeu, J.C. and Njomo, D. (2018) Thermomechanical Characterisation of Compressed Clay Bricks Reinforced by Thatch Fibres for the Optimal Use in Building. Materials Sciences and Applications, 9, 913-935.

https://doi.org/10.4236/msa.2018.912066

Received: August 27, 2018

Accepted: November 12, 2018

Published: November 15, 2018

Copyright (C) 2018 by authors and Scientific Research Publishing Inc. This work is licensed under the Creative Commons Attribution International License (CC BY 4.0).

http://creativecommons.org/licenses/by/4.0/

\section{cc) (i) Open Access}

\begin{abstract}
Thatch fibres grow in large quantity in the Adamawa region of Cameroon. During the long dry season, these fibres cause numerous fire incidents, which not only devastate large areas of cash crops, but also contribute to increase emissions of greenhouse gases into the atmosphere. This article aims to show how fibres could be used with compressed clay bricks to manufacture an insulating material used in building. Four fibre contents 1\%, 2\%, 3\% and 4\% made up the sample studied. The asymmetric hot plate methodology was used to determine the thermophysical properties of these composite materials. The volumetric heat capacity and the thermal effusivity of these materials were estimated. These two parametres were used to determine their apparent thermal conductivities. The results obtained show that the thermal conductivity decreases as the volume of fibres in the mixture increases. It is $0.689 \mathrm{~W} \cdot \mathrm{m}^{-1} \cdot \mathrm{K}^{-1}$ for simple compressed clay bricks and $0.510 \mathrm{~W} \cdot \mathrm{m}^{-1} \cdot \mathrm{K}^{-1}$ for a dosage at $3 \%$ of thatch fibres. In a bit to validate the results of the pilot study of the apparent thermal conductivity, the heat mass capacity of this composite material was achieved through the use of the dehydration method. The relative difference obtained with the results of the volumetric heat capacity carried out with these two methods was good. All results showed that the use of fibres in compressed laterite brick gives a more insulating composite material that respects Civil Engineering Norms.
\end{abstract}

\section{Keywords}

Thatch Fibres, Clay Bricks, Thermo Mechanical Properties, Transient Method, Mixing Method 


\section{Introduction}

The tendency of the $21^{\text {st }}$ century in industrialised nations is to limit the impact of human activity on the environment. It is thus within this context that construction industries had to innovate its construction practices in order to improve the use of energy in buildings as well as proposing cutting-edge technologies on materials that meet new user demands and environmental impact laws. Greenhouse gases emission, which makes up one of the main cause of environmental pollution, is constantly on the rise. These gases touch a wide range of sectors such as: agriculture, waste treatment plant, industries, transportation, and building construction etc. The global emission rate of greenhouse gas (GHG) in the Building sector is $4.1 \mathrm{Gt}$ eq $\mathrm{CO}_{2}$ (gigatonnes in $\mathrm{CO}_{2}$ equivalent) in 2016 [1]. According to Meggers et al. [2] the building sector alone is responsible for $35 \%$ of world emission of carbon dioxide $\left(\mathrm{CO}_{2}\right)$. This figure is steadily on the rise and can reach $50 \%$ by the year 2050. In Africa, particularly in Cameroon, the figures are alarming. Since 2012, energy production is not commensurate to its consumption. The highest energy consumption units have artificial air-conditioners to ensure better heat control. For a better control of energy use in a building, the use of a good local isolating material with high emitting heat ability and hygroscope is recommended. Heat emission will help curb the high energy consumption in the building currently with air-conditioner that doesn't meet current international standards. This situation is very regular in the Sahelian regions of Cameroon with its hot tropical climate [3]. However, in order to reduce global warming and improve on the heat emission in buildings, laterite soil mixture is used to make composite material applied in the interior of the building to ensure its better heat insulation.

Our research is therefore, based on this concept of the used of laterite composite material as insulant in the interior of buildings. The sample composite material used in this study is laterite bricks mixed with thatch fibres all from the locality of Meiganga. In the Adamawa region of Cameroon, otherwise known as Watershed, $80 \%$ of houses are built with laterite brick not industrially treated nor having any geotechnical, mechanical, thermophysical or acoustic characterisation prepared initially. The bricks used do not meet civil engineering standards. A lot of research works have been carried out in the domain of characterisation of composite material made from laterite soil. Meukam et al. [4] have shown that cement stabilized clay bricks mixed with pozzolan have good mechanical strengths and low thermal conductivities. Lamharouet et al. [5] demonstrated how thermal characteristics of Larache locality (Morocco) change considerably when stabilized with a proportion of cement. Bal et al. [6] on their part studied the lateritic clay bricks of Senegal. They used the asymmetric hot plate method to estimate the thermal conductivities when used in a mixture with millet pod fibres. They went further to show that mixture with that fibre drastically reduces its thermal conductivity. But as limitation, his work didn't show to which extend the fibre content of the composite material created respected Civil 
Engineering Standards. Meukam et al. [7] worked on the thermal-mechanical characteristics of laterite bricks in the Centre region (Yaounde) of Cameroon solidified with cement on one hand and on the other with the use of a substance like pouzzolan. Thermophysical characterisation with box method confirmed that using pozzolan, leads to better insulating material. Damfeu et al. [8] modelled the thermal properties of insulating plant fibres using the box asymmetric hot plate and radial flow methods. They demonstrated that the apparent thermal conductivity of kapok and coconut fibre could be used as substitute to synthetic insulating materials such as polyester or glass fibre. Probably, the use of an additional element in making a laterite brick would have led to good insulating composite material. Damfeu et al. [9] in another write up show the modelling and assessing of aggregate thermal properties of construction materials and went further to justify that red pouzzolan aggregates has a smaller thermal effusivity and conductivity than the black aggregate pouzzolan. Their complementary role in the making of laterite brick could therefore improve its thermal performance. Elhamdouni et al. [10] studied the thermophysical and mechanical characterisation of reinforced clay bricks with alfa or straw fibres. The results showed that the use of straw fibres help reduce the thermal conductivity energy to $2 \%-7 \%$ as compared to alfa fibre. Nevertheless, they went further to demonstrate that alfa fibre can improve mechanical performance of clay material as compared to clay straw material (with an increase of $8 \%-17 \%$ of the flexural strength and $6 \%-18 \%$ of compressive strength). Although most of these studies seek to improve the thermal insulating capacity of the sample materials, the findings still did not corollate with that of the pilot studies, especially with that of the apparent thermal conductivity. These results do not always reflect the conditions of its use compared to Civil Engineering standards.

This work has as main objective the enhancement of thatch fibres as thermal insulation in buildings to reduce the quantity usually burnt during the long dry season. It was assessed when mixed with laterite bricks to get the thermophysical properties. This material can be used to curb energy consumption when used as filling for buildings.

\section{Materials and Methods of Mechanical Characterization}

\subsection{Materials}

\subsubsection{Laterite}

Around the Meiganga vicinity, more than $80 \%$ of houses are built with laterite soil as opposed to the West Region of Cameroon where the laterite soil is rather dry. Although the objective is to get a composite material with insolation properties, it's however imperative to begin with a mastery of the geotechnical properties of the sample laterite soil. Cameroon Civil Engineering standards stipulates (CS: 102 - 114) that, filling material for building such as compressed terracotta brick wall recommended for making laterite bricks should be used with plasticity index of $I_{p} \leq 30 \%$ [11] [12]. The laterite (Figure 1) studied in this re- 
search project was taken from Meiganga. The water content of laterite soil sample as of escavation is $15 \%$ got from the Equation (1):

$$
W=100 \frac{P_{h}-P_{s}}{P_{s}}
$$

where: $P_{h}$ is the mass of soil sample in its natural state and $P_{s}$ is the mass of the soil sample after passing through heat for $105^{\circ} \mathrm{C}$ for 24 hours.

In order to determine the physico-chemical and mineralogical characteristics of this laterite, a grading analysis (according to BS 1377: 1975 [11]) was carried out in a bit to check if the excavated laterite sample contained much clay and therefore, needed rectification before use. Following the size of particles obtained with the help of an electric sieve i.e. with diametre between $1 \leq D(\mu \mathrm{m}) \leq$ 100 undergone a particle size grading study and that of diametre between $100 \leq$ $D(\mu \mathrm{m}) \leq 6500$ underwent a sediment metric particle size grading study. Two equations were used to calculate the diametres of the particles used to represent the diagram of the texture of this laterite.

- The diametre of particles is given by the stockes Law

$$
D^{2}=\frac{18 \eta U}{g\left(\gamma_{s}-\gamma_{w}\right)}
$$

- For the percentage of the diametre particles inferior to $D$, we use the equation

$$
\leq D=\frac{\gamma_{s}\left(C_{3} L+C_{4}\right)}{P_{S}\left(\gamma_{s}-\gamma_{w}\right)}(1-(\geq 2.38))
$$

where: $\gamma_{s}=26.5 \times 10^{3} \mathrm{~N} \cdot \mathrm{m}^{-3}$ is the bulk specific weight of the solid particles; $\gamma_{w}=10 \mathrm{~N} \cdot \mathrm{m}^{-3}$ is the bulk specific weight of water; $g$ is accelerating gravity in $\mathrm{cm} \cdot \mathrm{s}^{-2} ; U$ is the falling speed of particles in $\mathrm{cm} \cdot \mathrm{s}^{-1}, \eta$ is the fluid viscosity measured in poise; $C_{3}$ is the conversion coefficient from 1/1000; $C_{4}$ is the reading for water only and $L$ is the vertical reading $1 / 1000$ beyond one.

The results from Equations (2) and (3) enabled us to represent the texture diagram presented in Figure 2.

Distribution of particle size grading analysis of laterite soil as illustrated in Table 1.

In analysing the diagram in Figure 2, we noticed that the texture curve of the laterite soil did not entirely fall under the grading range, moreover, the analysis of the summary in (Table 1) show the clay nature of the soil with a $(38.85 \%)$ which is well above the limit recommended by the Cameroonian standard $\mathrm{CN}$ : $102-114$ for the design of BTC which is $30 \%$ [11] [12] [13]. This result is rather interesting to us because in the samples to be made, thatch fibres would be integrated without the use of stabilisers like cement or lime. It is needless to treat laterite before using because the more the use, the more clay it contains. We equally brought out the limitations of Atterberg's work at the level of water and plastic limitation in laterite soil. Not having used the shock number $(N)$ method directly equal to 25 shocks, we used the equation to calculate the liquidity and the plasticity limit of each test: 


$$
\begin{gathered}
W_{L}=\frac{W}{1.419-0.3 \log N} \\
W_{P}=100 \frac{M_{t h}-M_{t s}}{M_{t s}-M_{t}}
\end{gathered}
$$

where: $M_{t}$ tare mass; $M_{t h}$ is tare mass + wet sample; $M_{t s}$ is tare mass + dry sample

Placticity index $I_{P}$ of laterite came from the equation:

$$
I_{p}=W_{L}-W_{p}
$$

Table 2 shows limitation of Atterberg laterite

We can then conclude that though the laterite texture curve does not fall within the grading range, its plastic index meets BTC conception standards that stipulates that Atterberg's limitation must be between $10<I_{p}<20$. The laterite was not adulterated with in anyway.

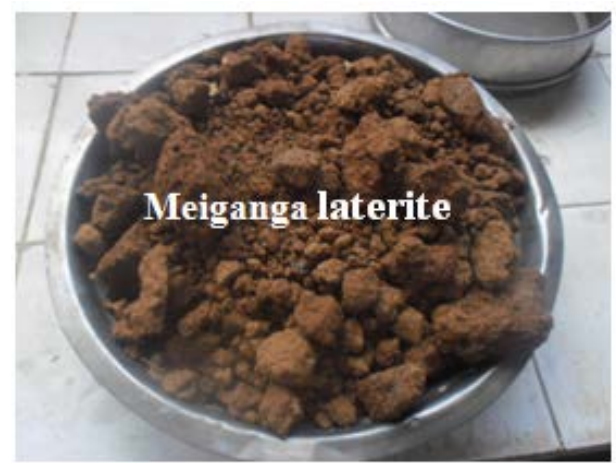

Figure 1. Lateritic soil.

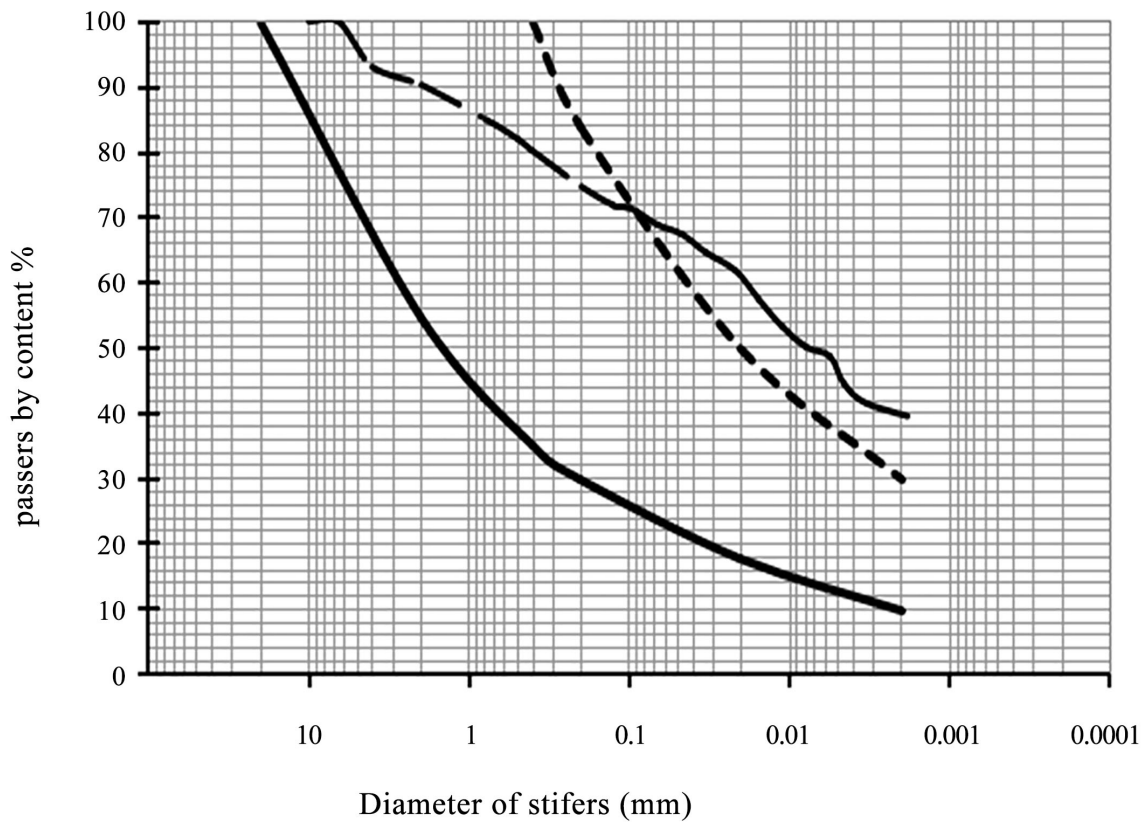

Mimimun limit

Maximun limit $\because \ldots$ gramulometric grading

Figure 2. Diagram showing texture of Laterite from Meiganga. 
Table 1. Summary analysis of particle size grading.

\begin{tabular}{ccccccc}
\hline Ref & colour & Aspect & $\begin{array}{c}\text { \% gravel } \\
\Phi>2 \mathrm{~mm}\end{array}$ & $\begin{array}{c}\text { \% of sand } \\
2>\Phi>0.02 \mathrm{~mm}\end{array}$ & $\begin{array}{c}\text { \% of limons } \\
0.02>\Phi>0.02 \\
\mathrm{~mm}\end{array}$ & $\begin{array}{c}\text { \% of clay } \\
\Phi<0.02 \mathrm{~mm}\end{array}$ \\
\hline Late & Red & Clay-Sandy & 6.67 & 34.34 & 23.02 & 38.85 \\
\hline
\end{tabular}

Late: Lateritic soil.

Table 2. Atterberg limitations.

\begin{tabular}{cccc}
\hline Material & $W_{L}(\%)$ & $W_{P}(\%)$ & $I_{P}(\%)$ \\
\hline Lateritic & 56 & 38.3 & 17.7 \\
Cameroon Standards & $25-50$ & $20-35$ & $2-30$ \\
\hline
\end{tabular}

\subsubsection{Thatch Fibres}

Several researchers have worked on fibres as natural insulators that help improve thermal performance of a composite material. Petkova et al. [14] worked on the thermal properties of insulation material such as straw and even went further to show that the use of straw (less than $0.5 \%$ in mass) improves heat accumulation and thermal insulating properties of the ecological composite material. Azahry et al. [15] carried out a study of the energy efficiency and thermal properties of the clay-straw of composite material thereby; high-lighting its important thermal properties for heat storage and temperature regulation during winter day and night. He also proved that this material can withstand extreme temperature (hot or cold) without any cooling or heating system. Kossi et al. [16] looked at the mechanical and thermal characterisation of compact soil blocks with straw or cement that have different percentages and even went further to show that the thermal conductivity decreases in relation to the proportion of fibres used. But our study dwelt on natural fibres from thatch as shown in Figure 3.

The process of extracting dry fibres uses as follow:

- The fibres were picked wet (Figure 3(a));

- Chopped at regular length and dried in the open (Figure 3(b));

- After the crushed stem mixed with lateritic soil (Figure 3(c));

- They were later dried in an oven at $45^{\circ} \mathrm{C}$ (Figure 3(d)) for 48 hours;

- After that they were packed in plastic bags so as to keep their water content close to zero.

Measuring the apparent density of dry fibres (Table 3) shows the light fibres.

The dry fibres obtained are then mixed with the laterite at different proportions to get different samples of composite material.

\subsubsection{Mixed Composition of Flexural and Compressive Strengths}

The experimental setup used in making samples were made of three cuboid-shaped metallic mould of (width 1, length $\mathrm{L}$ and thickness h): $4 \mathrm{~cm} \times 8 \mathrm{~cm}$ $\times 2 \mathrm{~cm}$ (French standards Crater standard NFP-31-212 [11]) for the Bending test (Figure 4(a)), another square shape of $4 \mathrm{~cm} \times 4 \mathrm{~cm} \times 4 \mathrm{~cm}$ (standard NFP-98-335 [11]) for the Compression test (Figure 4(b)) and of rectangular shape $10 \mathrm{~cm} \times 10 \mathrm{~cm} \times 3 \mathrm{~cm}$ for the thermophysical characterisation tests 
(Figure 4(c)). The hydraulic press used for compacting is suitable for sample design for three-point bending, tensile and simple compression tests. The specimens produced were maintained at 32 days of cure. Table 4 shows the different samples made.

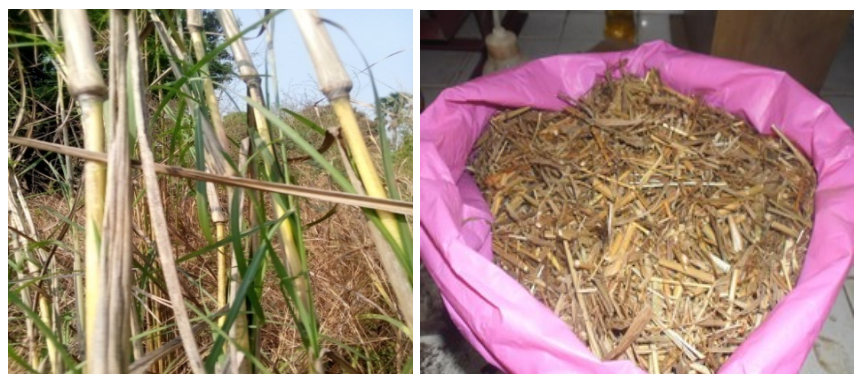

(a)

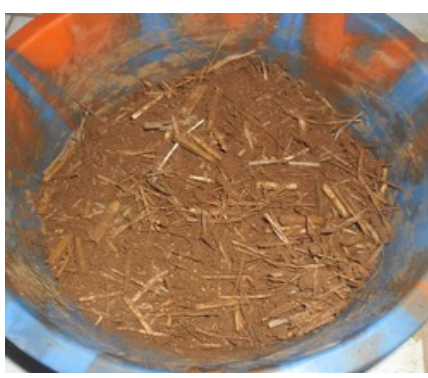

(c) (b)

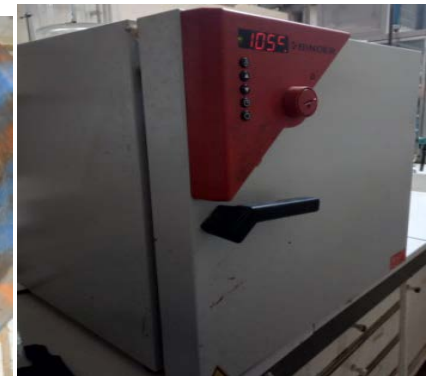

(d)

Figure 3. Natural thatch fibres: (a) stem of fibres; (b) dry stem; (c) crushed stem mixed with lateritic soil; (d) oven for drying sample.

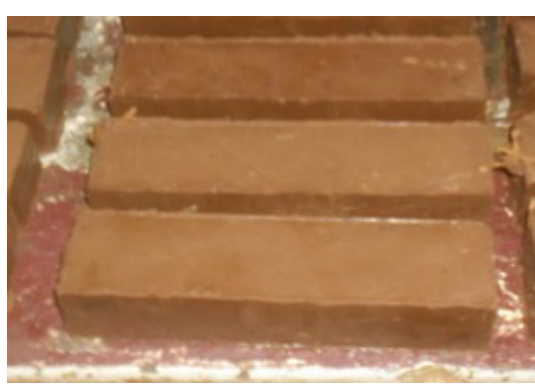

(a)

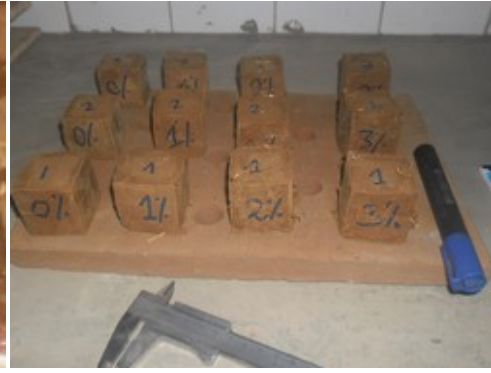

(b)

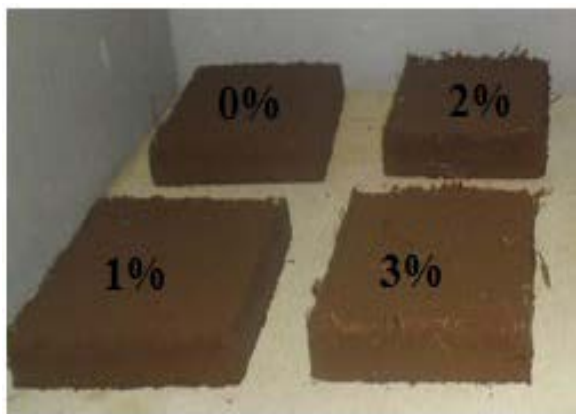

(c)

Figure 4. Samples for: (a) bending test; (b) compression test; (c) thermophysical characterisation test. 
Table 3. Apparent density of dry fibres.

\begin{tabular}{cccc}
\hline Ref & $M_{S}(\mathrm{~g})$ & $V_{f}(\mathrm{ml})$ & $\rho_{\text {app (f) }}\left(\mathrm{kg} \cdot \mathrm{m}^{-3}\right)$ \\
\hline Fibres & 9 & 170 & 52.91 \\
\hline
\end{tabular}

$M_{\dot{s}}$ dry mass of fibres; $V_{\dot{f}}$ volume of fibre; $\rho_{\text {app }(f)}:$ Apparent density of dry fibre.

Table 4. Samples composition.

\begin{tabular}{ccccccccccc}
\hline \multicolumn{2}{c}{ Samples for: } & \multicolumn{3}{c}{$\begin{array}{c}\text { Flexural } \\
16 \mathrm{~cm} \times 4 \mathrm{~cm} \times 4 \mathrm{~cm}\end{array}$} & \multicolumn{2}{c}{$\begin{array}{c}\text { Compressive } \\
4 \mathrm{~cm} \times 4 \mathrm{~cm} \times 4 \mathrm{~cm}\end{array}$} & \multicolumn{3}{c}{$\begin{array}{c}\text { Thermophysical } \\
10 \mathrm{~cm} \times 10 \mathrm{~cm} \times 3 \mathrm{~cm}\end{array}$} \\
\hline Ref & Fbre (\%) & $m_{L}(\mathrm{~g})$ & $m_{F}(\mathrm{~g})$ & $V(\mathrm{l})$ & $m_{L}(\mathrm{~g})$ & $m_{F}(\mathrm{~g})$ & $V(\mathrm{l})$ & $m_{L}(\mathrm{~g})$ & $m_{F}(\mathrm{~g})$ & $V(\mathrm{l})$ \\
E0 & 0 & 400 & - & 60 & 150 & - & 22.5 & 400 & - & 60 \\
E1 & 1 & 396 & 4 & 59.4 & 148.5 & 1.5 & 22.3 & 396 & 4 & 59.4 \\
E2 & 2 & 392 & 8 & 58.8 & 147 & 3 & 22 & 392 & 8 & 58.8 \\
E3 & 3 & 388 & 12 & 58.2 & 15.5 & 5.5 & 21.8 & 388 & 12 & 58.2 \\
\hline
\end{tabular}

$m_{L}(\mathrm{~g})$ : mass of laterite: $m_{F}(\mathrm{~g})$ : mass of fibres:; $V(\mathrm{l})$ : volume of water.

\subsection{Mechanical Characterisation Approach}

Mechanical characterisation is of prime importance in Civil Engineering. Depending on the nature of the material to be used, either as a load-bearing structure or as a filling of the building, this characterisation helps to verify whether the material meets Civil Engineering standards. In our case, filling materials were used in the interior of the building. We were therefore interested in two mechanical characteristics: Flexural and the Compressive strength.

\subsubsection{Flexural Strength}

Figure 5 shows the research tool used for measuring flexural strength

$F(\mathrm{~N})$ is flexural samples load (measured by CONTROLS.CAT machine No. T1004, Mat No. 3558), $D=50 \mathrm{~mm}$ distance from cylindrical support, $2 L=80 \mathrm{~mm}$ length of block and $h=20 \mathrm{~mm}$ the average thickness of block. The flexural strength of MPa calculated using the equation:

$$
R_{f}=\frac{3 F D}{2 L h}
$$

\subsubsection{Compressive Performance}

Figure 6 shows the research tool (cubic block).

If $\mathrm{F}$ is the compressive break-down load (observed in reading the machine CONTROLS No. of rings $4117, F_{\max }=30 \mathrm{kN}$ ), we then obtain $R_{C}$ constraint starting from the relation ( $h^{2}$ is the section):

$$
R_{C}=\frac{F}{h^{2}}
$$

\section{Thermophysical Characterisation Approach}

\subsection{Testing Device}

The testing tool used to show the thermophysical characterisation is the asym- 
metric hot plane method [6] [8]. It's a transient characterisation approach used to get the apparent thermal conductivity of a material (Equation (21)) by estimating the thermal effusivity $E$ and the volumetric heat capacity $\rho C_{P}$ in relation to the testing temperature $T_{\text {exp }}(t)$ and modelled temperature $T_{\text {mode }}(t)$. The testing instruments used for measuring the thermal properties are shown in Figure 7.

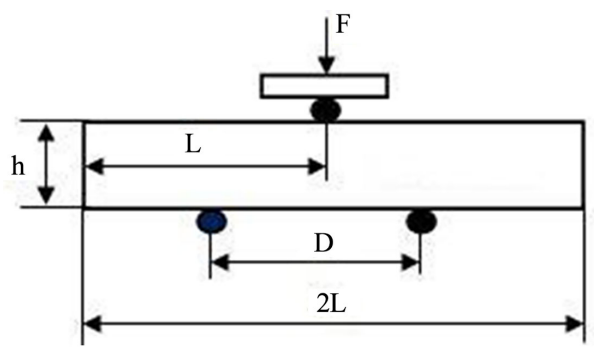

Figure 5. Research tool for flexural strength.

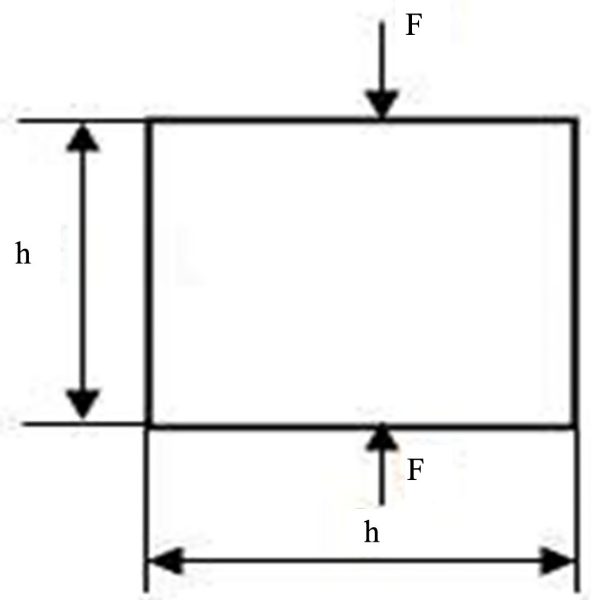

Figure 6. Compressive research tool.

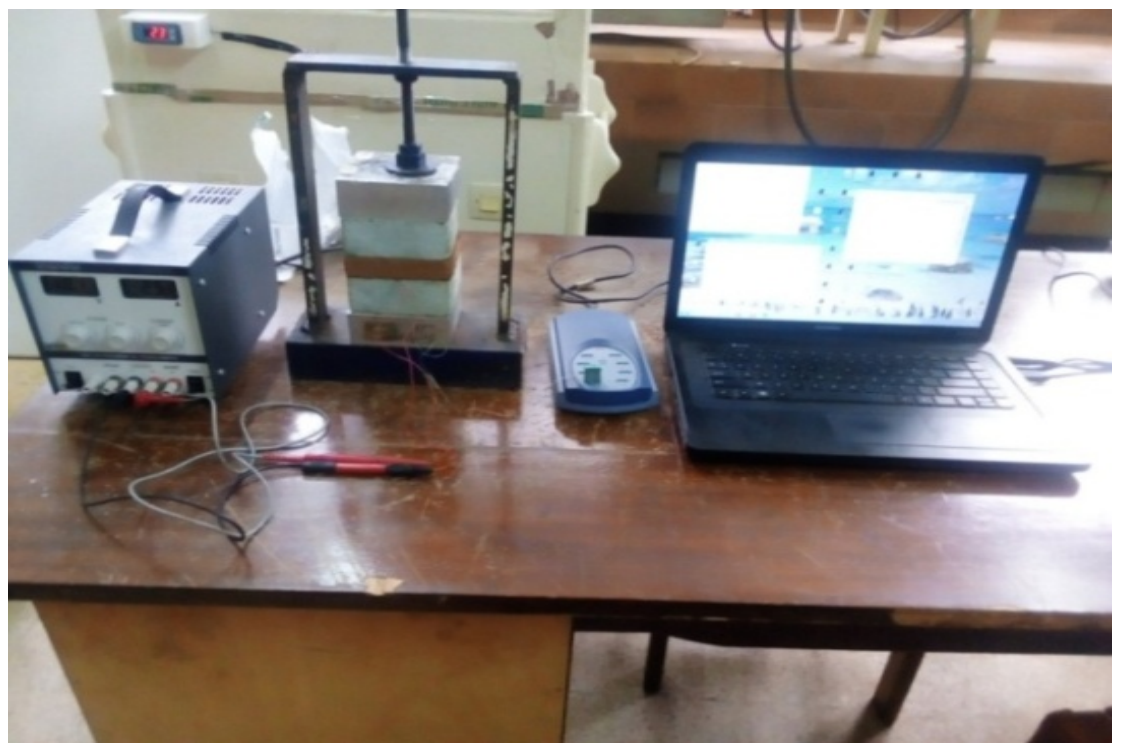

Figure 7. A cross-section of test instruments. 
Material with specifications of $(10 \mathrm{~cm} \times 10 \mathrm{~cm} \times 3)$ is placed on a heat sensor between two polystyrene blocks of $(10 \mathrm{~cm} \times 10 \mathrm{~cm} \times 5 \mathrm{~cm})$. A generator is used to heat the resistor. The increase in temperature at the centre of the heat resistor was as a result of type $K$ thermocouple that registers the test temperature on the hot surface of the material. The experimental temperatures $T_{\text {exp }}(t)$ were registered using the acquisition module TC 08-USB Picolog. The dropping of experimental and simulated temperature obtained after modelling the testing instrument helped us to estimate $E$ and $\rho C_{P}$. It is therefore important to note that the temperature above the polystyrene blocks remains at its initial state, to arrive at this; we placed two aluminium blocks of $10 \mathrm{~cm} \times 10 \mathrm{~cm} \times 4 \mathrm{~cm}$ above and below the polystyrene blocks.

\subsection{Quadrupoles Formalism of Heat Transfer}

Given that all the blocks used for the pilot test were thick, we could therefore model heat transfer to other blocks using the heat equation.

$$
\frac{\partial^{2} T_{i}}{\partial x^{2}}+\frac{\partial^{2} T_{i}}{\partial y^{2}}+\frac{\partial^{2} T_{i}}{\partial z^{2}}=\frac{1}{a_{i}} \frac{\partial T_{i}}{\partial t} \text { where } i=s \text { and } h
$$

where $T_{s}(x, y, z, t)$ modelises the temperature thermogram on the heated face of the composite material while $T_{h}(x, y, z, t)$ does same on the heat sensor. By assuming that the heat transfer remains unidirectional for a time $t$, solving this $1 \mathrm{D}$ equation can be done using the quadrupole formalism developed by Maillet et al. [17]. It is generally known that solving Equation (9) using the quadrupole formalism in the Laplace space leading us to a relation whose form is determined by Equation (10) below:

$$
\frac{\mathrm{d}}{\mathrm{d} x}\left(\begin{array}{l}
\theta \\
\phi
\end{array}\right)=M\left(\begin{array}{l}
\theta \\
\phi
\end{array}\right)
$$

where: $M$ is matrix or matrix product.

We can use this formalism according to the characterisation method used in evaluating thermophysical parameters $E, \rho C_{P}$ and $\lambda$. In this study, the asymmetrical hot plate method enables us to estimate by using the complete $1 \mathrm{D}$ model, the parametres $E$ and $\rho C_{P}$ yielding to $\lambda$.

\subsubsection{Simplified 1D Model}

Considering the sample and polystyrene insulating block as a semi-infinite medium and hoping that the heating sensor is a thin device (Figure 8), the equations can be written following the thermal flow traces across the sample (Equation (11)) or across the heating block (Equation (12)):

$$
\begin{gathered}
\left(\begin{array}{l}
\theta_{s} \\
\Phi_{h s}
\end{array}\right)=\left(\begin{array}{cc}
1 & 0 \\
\rho_{h} c_{h} e_{h} S p & 1
\end{array}\right)\left(\begin{array}{cc}
1 & S R_{h s} \\
0 & 1
\end{array}\right)\left(\begin{array}{c}
\theta_{1} \\
E \sqrt{p} \theta_{1}
\end{array}\right) \\
\left(\begin{array}{l}
\theta_{s} \\
\Phi_{h p o}
\end{array}\right)=\left(\begin{array}{ll}
A_{p o} & B_{p o} \\
C_{p o} & D_{p o}
\end{array}\right)\left(\begin{array}{c}
\theta_{2} \\
E_{p o} \sqrt{p} \theta_{2}
\end{array}\right)
\end{gathered}
$$




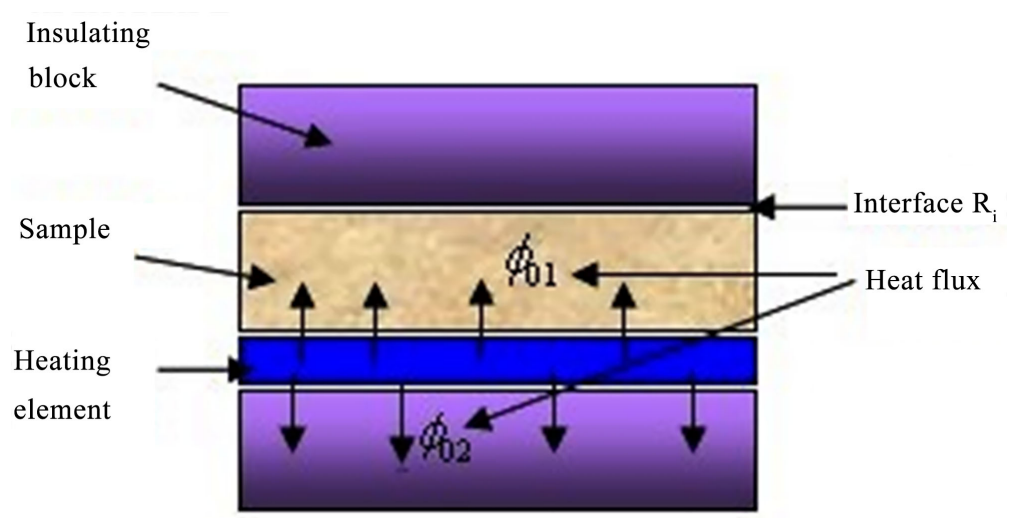

Figure 8. Across of the heat flow.

where: $E$ and $E_{p o}$ are respectively the thermal effusivity of samples and the polystyrene blocks while $P$ is the Laplace parametre; $S$ is the surface area of the sample which is supposed to be equal to $S_{h}$, area of heating element and $S_{p o}$, area of the polystyrene blocks.

Combining Equations (11) and (12) yields to:

$$
\theta_{s}(z, p)=\frac{1}{\frac{\rho_{h} c_{h} e_{h} p+\left(1+R_{h m} \rho_{h} c_{h} e_{h} S p\right) E \sqrt{p}}{1+R_{h m} E S \sqrt{p}}+\frac{E_{p o} \sqrt{p}}{1+R_{h p o} E_{p o} S \sqrt{p}}} \Phi(0, p)
$$

For a considerable period of time $(p \rightarrow 0)$, the analytic inversion of the above equation, using Laplace table gives:

$$
\Delta T_{\text {asym }}(0, t \rightarrow \infty)=\delta \sqrt{t}+\varphi S\left(\frac{E^{2} R_{h s}+E_{p o}^{2} R_{h p o}}{\left(E+E_{p o}\right)^{2}}-\frac{\rho_{h} c_{h} e_{h}}{S\left(E+E_{p o}\right)^{2}}\right)
$$

The pre-estimated thermal effusivity may be calculated with the simplified 1D model from numerical calculation of the slope $\delta(t)$ of the linear part of the curve $T(t)=f(\sqrt{t})$ when $T_{\text {exp }}(t)$ and $T_{\text {sint }}(t)$ are overlapped.

$$
E=E_{\text {pres }}=\frac{2 \varphi}{\delta \sqrt{\pi}}-E_{p o}
$$

The pre-estimated value of volumetric heat capacity given by the equation (15), may be approximated from the slope $\eta(t)$ of the linear part of the curve $T(t)=f(t)$ when $T_{\text {exp }}(t)$ and $T_{\text {sint }}(t)$ are overlapped.

$$
\left(\rho C_{p}\right)_{\text {pres }}=\frac{1}{e_{s}}\left(\frac{\varphi}{\eta}-\varphi_{p o} c_{p_{o}} e_{p o}-\rho_{h} c_{h} e_{h}\right)
$$

These pre-estimated values (Equations (15) and (16)) are then used as initial values in the estimation code of $E$ and $\rho C_{p}$ for complete model.

\subsubsection{Completed 1D Model}

With the Complete model, the quadrupole method no longer uses the sample and insulating block as in semi-infinite medium. Consequently, matrix $M$ representing these two blocks is shown in the Equation (17): 


$$
\left(\begin{array}{ll}
A_{s} & B_{s} \\
C_{s} & D_{s}
\end{array}\right)=\left(\begin{array}{cc}
\operatorname{ch}\left(\frac{\rho C_{p}}{E} \sqrt{p} e\right) & \frac{\operatorname{sh}\left(\frac{\rho C_{p}}{E} \sqrt{p} e\right)}{\lambda \frac{\rho C_{p}}{E} \sqrt{p}} \\
\lambda \frac{\rho C_{p}}{E} \sqrt{p} \operatorname{sh}\left(\frac{\rho C_{p}}{E} \sqrt{p} e\right) & \operatorname{ch}\left(\frac{\rho C_{p}}{E} \sqrt{p} e\right)
\end{array}\right)
$$

and

$$
\left(\begin{array}{cc}
A_{p o} & B_{p o} \\
C_{p o} & D_{p o}
\end{array}\right)=\left(\begin{array}{cc}
c h\left(\sqrt{\frac{p}{a_{p o}}} e_{p o}\right) & \left.\frac{\operatorname{sh}\left(\sqrt{\frac{p}{a_{p o}}} e_{p o}\right.}{\lambda_{p o}}\right) \\
\lambda_{p o} \sqrt{\frac{p}{a_{p o}}} \\
\lambda_{p o} \sqrt{\frac{p}{a_{p o}}} \operatorname{sh}\left(\sqrt{\frac{p}{a_{p o}}} e_{p o}\right) & \operatorname{ch}\left(\sqrt{\frac{p}{a_{p o}}} e_{p o}\right)
\end{array}\right)
$$

The solving of the matrix system equation is given by Equations (18) and (19):

$$
\begin{aligned}
&\left(\begin{array}{l}
\theta_{c} \\
\Phi_{h s}
\end{array}\right)=\left(\begin{array}{cc}
1 & 0 \\
\rho_{h} c_{h} e_{h} S p & 1
\end{array}\right)\left(\begin{array}{cc}
1 & S R_{h s} \\
0 & 1
\end{array}\right)\left(\begin{array}{cc}
A_{s} & B_{s} \\
C_{s} & D_{s}
\end{array}\right)\left(\begin{array}{cc}
1 & S R_{s p o} \\
0 & 1
\end{array}\right)\left(\begin{array}{cc}
A_{p o} & B_{p o} \\
C_{p o} & D_{p o}
\end{array}\right)\left(\begin{array}{c}
0 \\
\Phi_{m}
\end{array}\right) \\
&=\left(\begin{array}{cc}
A & B \\
C & D
\end{array}\right)\left(\begin{array}{c}
0 \\
\Phi_{1}
\end{array}\right) \\
&\left(\begin{array}{c}
\theta_{c} \\
\Phi_{h p o}
\end{array}\right)=\left(\begin{array}{cc}
1 & S R_{h p o} \\
0 & 1
\end{array}\right)\left(\begin{array}{cc}
A_{p o} & B_{p o} \\
C_{p o} & D_{p o}
\end{array}\right)\left(\begin{array}{c}
0 \\
\Phi_{2}
\end{array}\right)
\end{aligned}
$$

The total heat flux density in the Laplace field is calculated from relation:

$$
\Phi_{0}=\Phi_{1}+\Phi_{2}
$$

Combining relations (18); (19) and (20), the system leads to:

$$
\theta_{c}(z, p)=\frac{B_{p o} B_{s}}{D_{s} B_{p o}+D_{p o} B_{s}} \Phi(0, p)
$$

The theoretical curve $T_{\text {asym }}(t)=L^{-1}\left(\theta_{c}(z, p)\right)$ was obtained by numerical inversion of the Equation (21) using the De Hoog algorithm [18]. The Levenberg Marquert algorithm [19] [20] used with Matlab helps to calculate the $E$ and $\rho C_{p}$ parametres with the complete model. This assessment can only drop when converged (reducing the sum of the quadratic difference: Equation (22)) between the experimental curve $\Delta T_{\text {exp }}(t)=T(0, t)-T_{a}$ and theoretical curve, taking as initial values the pre-estimated values (Equations (15) and (16)).

$$
\Sigma=\sum_{i=1}^{n}\left[\Delta T_{\text {exp }}\left(t_{i}\right)-T_{\text {asym }}\left(t_{i}\right)\right]^{2}
$$

The calculated values of apparent thermal conductivity of composite material can also be inferred from the Equation (23):

$$
\lambda_{\text {est }}=\frac{E^{2}}{\rho C_{p}}
$$




\section{Research Procedure for Measuring Thermal Capacity $C_{p}$}

Establishing thermal capacity of composite material with different fibre proportions that was achieved had as objective to confirm the results of the pilot study carried out with Equation (23). This test achievement was made known through its water content, colometry sizing which helps to validate the results. To establish the water content, several methods do exist among which the dehydration method (DM) uses in this research. Three research instruments (Figure 9) were used to get the results of the pilot study: drying oven regulated at $105^{\circ} \mathrm{C}$ for $24 \mathrm{~h}$ to dry the sample; Omega Engineering probe; Dewar Vapour calorimetre $12 V_{\max }$.

\subsection{Method of Determining $C_{P}$}

This method was inspired by the manner in which objects transfer heat. The $C_{p}$ was measured in cold water as well as normal temperature. The thermal heat emitted by the object is as follows:

$$
Q=m C_{m} \Delta \theta
$$

In cases where heat loss is neglected within the exchange system, we can therefore conclude that the energy produced by the object is exactly equivalent to that absorbed by water:

$$
Q_{h w}+Q_{c w}+Q_{c a}=0
$$

where $Q_{h W}$ equals energy emitted by the object, $Q_{c W}$ energy absorbed by water and $Q_{c a}$ energy absorbed by calorimeter.

For calorimeter sizing, the following equation was used:

$$
m_{2} C_{e}\left(\theta_{e q}-\theta_{i}\right)+C\left(\theta_{e q}-\theta_{i}\right)+m_{2} C_{e}\left(\theta_{e q}-\theta_{c}\right)=0
$$

If the mass of hot water is equal to that of cold water, we'll then say that:

$$
C=\frac{m_{2} C_{e}\left(2 \theta_{e q}-\theta_{i}-\theta_{c}\right)}{\theta_{i}-\theta_{e q}}
$$

To determine the $C_{p}$ sample; we have:

$$
m_{1} C_{e}\left(\theta_{e q}-\theta_{i}\right)+C\left(\theta_{e q}-\theta_{i}\right)+m_{2} C_{p}\left(\theta_{e q}-\theta_{w o}\right)=0
$$

Leading to:

$$
C_{p}=\frac{m_{1}\left(C_{e}+C\right)\left(\theta_{e q}-\theta_{i}\right)}{m_{2}\left(\theta_{w o}-\theta_{e q}\right)}
$$

where: $m_{1}$ mass of hot water, $m_{2}$ mass of cold water, $\theta_{c}$ hot water temperature, $\theta_{w o}$ Cold water temperature, $\theta_{e q}$ balance point, Calorie capacity of calorimeter

\subsection{Experimental Result of $C_{p}$}

To validate the research method used, we tested the value of the thermal capacity of the calorimeter used. The specification sheet provided shows $C_{P}=30 \mathrm{~J} \cdot \mathrm{K}^{-1}$. (Table 5). 
We notice a correlation between the average value of the thermal capacity of calorimeter calculated with dehydration method and that shown on the researcher's specification sheet. The relative difference obtained between the two values is less than $3 \%$. This result enables us to validate the results of the thermal capacities of the composite materials studied. Table 6 presents the set of experimental results obtained for samples $E 0, E 1, E 2, E 3$ and $E 4$.

\section{Discussion of Findings}

Measurements were carried out on five different samples $E 0, E 1, E 2, E 3$ and $E 4$.

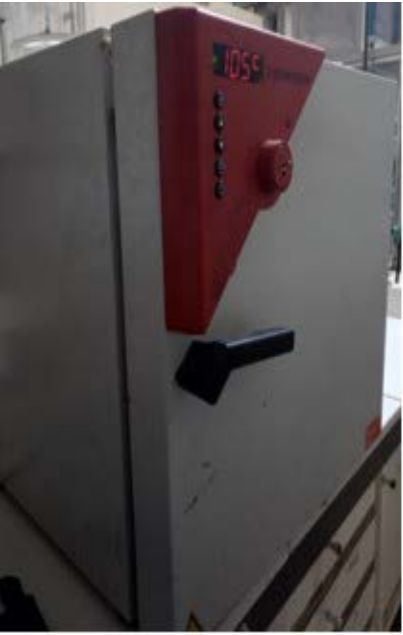

(a)

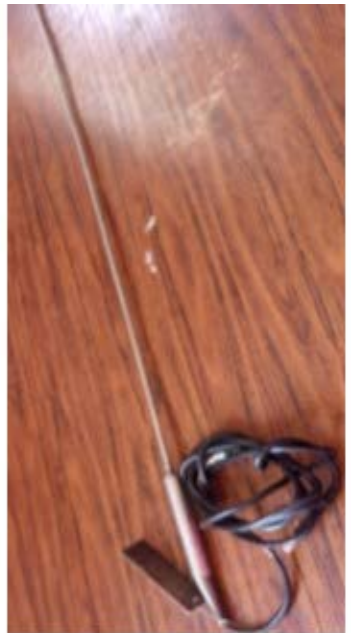

(b)

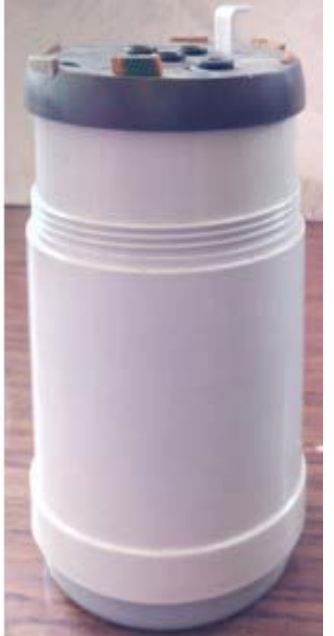

(c)

Figure 9. Testing material for establishing thermal heat capacity; (a) Adjustable oven; (b) Omega engineering probe; (c) Dewar vapor calorimetre.

Table 5. Equilibrium temperatures and thermal heat capacity $C_{p}$ of the calorimeter obtained.

\begin{tabular}{ccccccccc}
\hline Test $^{0}$ & $M_{c e}(\mathrm{~g})$ & $M_{h e}(\mathrm{~g})$ & $T_{c e}\left({ }^{\circ} \mathrm{C}\right)$ & $T_{h e}\left({ }^{\circ} \mathrm{C}\right)$ & $T_{e q}\left({ }^{\circ} \mathrm{C}\right)$ & $C_{p}\left(\mathrm{~J} \cdot \mathrm{K}^{-1}\right)$ & $\left(C_{p}\right)_{\text {mean }}\left(\mathrm{J} \cdot \mathrm{K}^{-1}\right)$ & $D(\%)$ \\
\hline 1 & 200 & 200 & 22 & 81 & 52 & 28.827 & & \\
2 & 200 & 200 & 22 & 81 & 52 & 28.827 & 29.17 & 2.76 \\
3 & 200 & 200 & 24 & 81 & 53 & 29.85 & & \\
\hline
\end{tabular}

$M_{c e}:$ Mass of cold water; $M_{h e}$ : Mass of hot water; $T_{c e}$ cold water temperature; $T$ : hot water temperature; $D$. deviation.

Table 6. Experimental thermal capacity of samples.

\begin{tabular}{cc}
\hline Ref & $C_{p(D M)}\left(\mathrm{Jkg}^{-1}\right)$ \\
\hline$E 0$ & 870.46 \\
$E 1$ & 869.57 \\
$E 2$ & 867.18 \\
$E 3$ & 861.73 \\
$E 4$ & 858.43 \\
\hline
\end{tabular}


Three were performed on each sample as well as the average value of each of the samples. For the mechanical tests, Table 7 summarizes all the experimental results.

We notice that the apparent density $\rho_{\text {app }}$ and the porosity $\varepsilon$ were subsequently obtained from the Equation (30):

$$
\begin{gathered}
\rho_{a p p}=\frac{M_{s}}{V_{a p p}} \\
\varepsilon=\frac{\rho_{a p p s}}{\rho_{e}} \frac{M_{h}-M_{s}}{M_{s}}
\end{gathered}
$$

where: $V_{a p p}$ is the apparent density of the composite material, $M_{h}$ wet density of composite material, $M_{s}$ is dry density of composite material and $\rho_{e}$ is the mass density of water.

It should be noted that control protocol on building site recommended by MIPROMALO (Mission de Promotion des Matériaux Locaux) [12] BTC dry compressive strength and with a 14 day greater than $2 \mathrm{MPa}$. Generally, cases with filling material of $0.6 \leq R_{C} \leq 1 \mathrm{MPa}$ blocks should be used to construct houses with first floor and large borders. Figure 10 represents the compressive strength of bricks made according to the proportion of fibres. We noticed that as quantity of fibres increases, so is the solidity of the compressive strength of the composite material. The reverse was supposed to be true, but since the lateritic soil used is very rich in clay, these thatch fibres from the Adamawa region, known for its firm stems (especially when dried) would however, naturally increase the strength of these bricks. At the same time adding fibres increase the porosity (Figure 11) of the material and being too clayish, it therefore creates micropores that help increase the insulation power as well as its flexural strength. (Figure 12) Looking at the most general case, that is: standards of construction on the compressive samples $R_{C} \geq 2 \mathrm{MPa}$ of the observation results, we found out that the brick can be used even at a grade of $4 \%$ in fibres content.

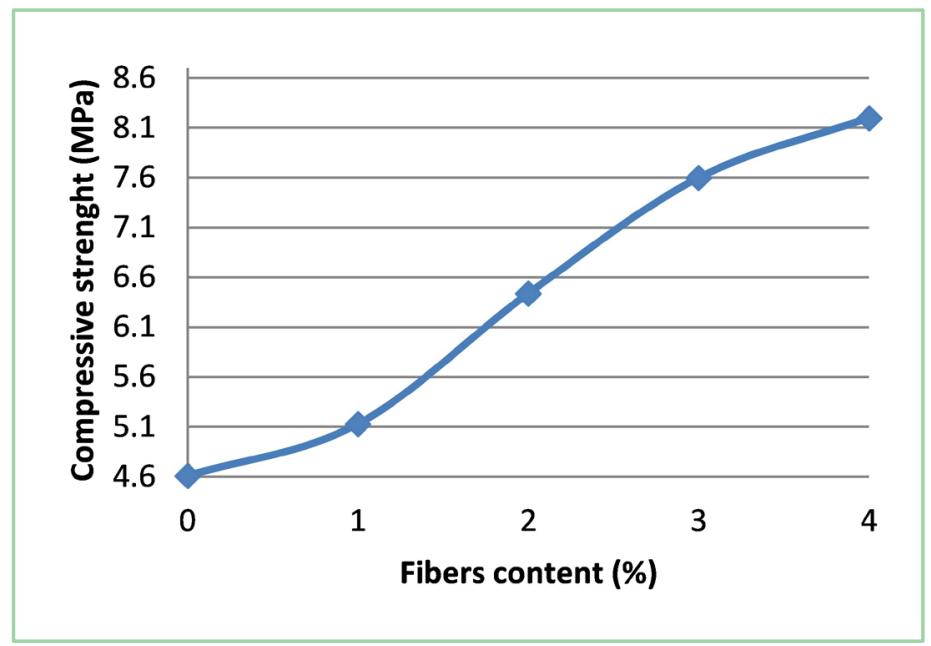

Figure 10. Compressive strength of 28 days according to the fibrous content. 


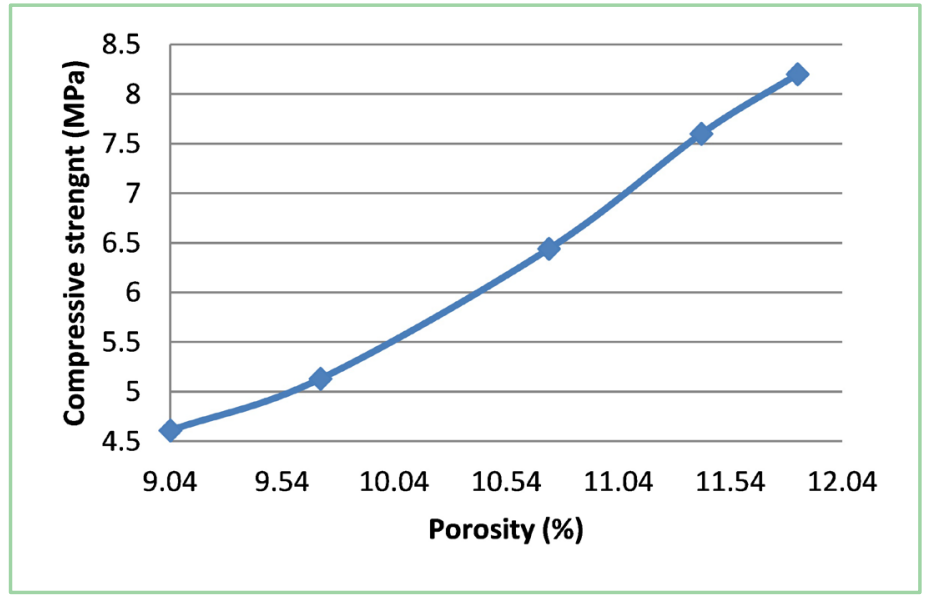

Figure 11. Compressive strength of 28 days according porosity of composites materials.

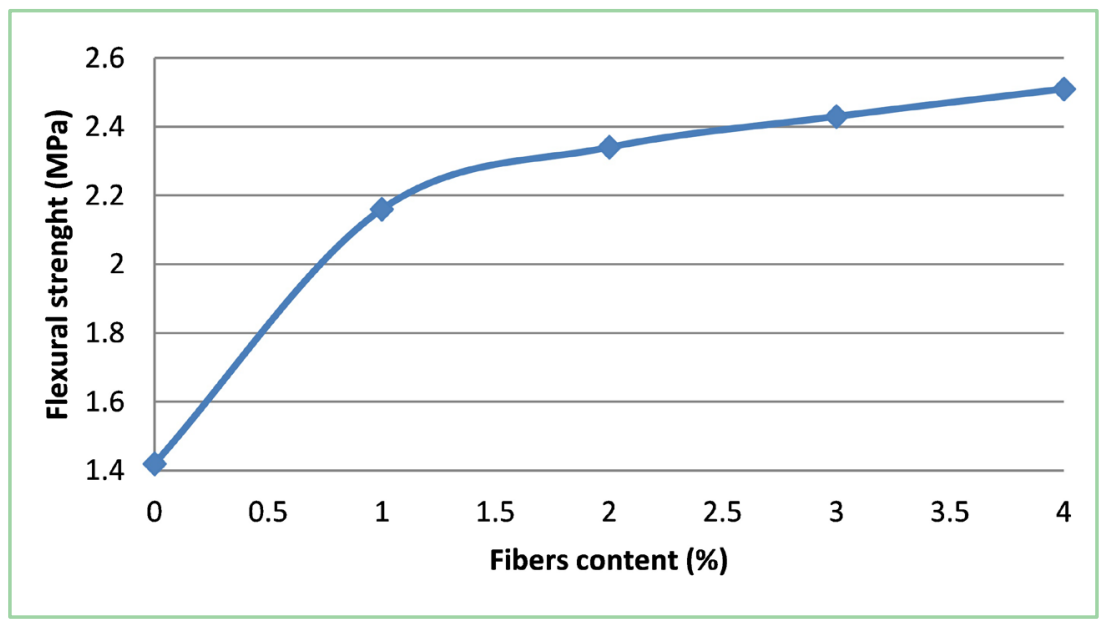

Figure 12. Flexural strength to 28 days according to the fibrous content.

Table 7. Result of mechanical experiment.

\begin{tabular}{cccccc}
\hline Ref & $\rho_{\text {app }}\left(\mathrm{kg} \cdot \mathrm{m}^{-3}\right)$ & $R_{C}(\mathrm{MPa})$ & $R_{F}(\mathrm{MPa})$ & $\varepsilon$ & $\mathrm{Abs}$ \\
\hline$E 0$ & 1775.86 & 4.61 & 1.42 & 9.04 & 16.18 \\
$E 1$ & 1770.61 & 5.13 & 2.06 & 9.71 & 17.19 \\
$E 2$ & 1751.91 & 6.44 & 2.34 & 10.73 & 17.73 \\
$E 3$ & 1745.95 & 7.60 & 2.43 & 11.41 & 18.75 \\
$E 4$ & 1741.66 & 7.92 & 2.57 & 13.01 & 19.21 \\
\hline
\end{tabular}

As concerns thermophysical characterisation, we initially verified if the new model could react to thermophysical properties when calculated with transient hot plate method. Since these thermophysical parametre are not yet known, we noticed a reduced sensitivity of the thermophysical parametres $\beta \frac{\partial T}{\partial \beta}$ by using the result obtained with the simplified model (Equations (15) and (16)) Values $E_{\text {pres }}$ and $\left(\rho C_{p}\right)_{\text {pres }}$ were calculated within a period of time $\left[t_{1}, t_{2}\right]$ as much as the 
thermogram $T_{\text {asym }}(t)$ and $T_{\text {sint }}(t)$ superimposed (Figure 13(a)). For example, with the case of sample E3, the numerical calculations of slope $\delta$ and $\eta$ (Figure 13(b)) between limits $100-150 \mathrm{~s}$ gave us: $E_{\text {pres }}=878.34 \mathrm{~J} \cdot \mathrm{m}^{-2} \mathrm{~K}^{-1} \cdot \mathrm{s}^{-1 / 2}$ and $\left(\rho C_{p}\right)_{\text {pres }}=$ $1.531 \times 10^{6} \mathrm{~J} \cdot \mathrm{m}^{-3} \cdot \mathrm{K}^{-1}$.

The reduced sensitivities of the temperature of parameter $E, \rho C_{p}$ and $S R_{c h s}$ were calculated as presented in Figure 14.

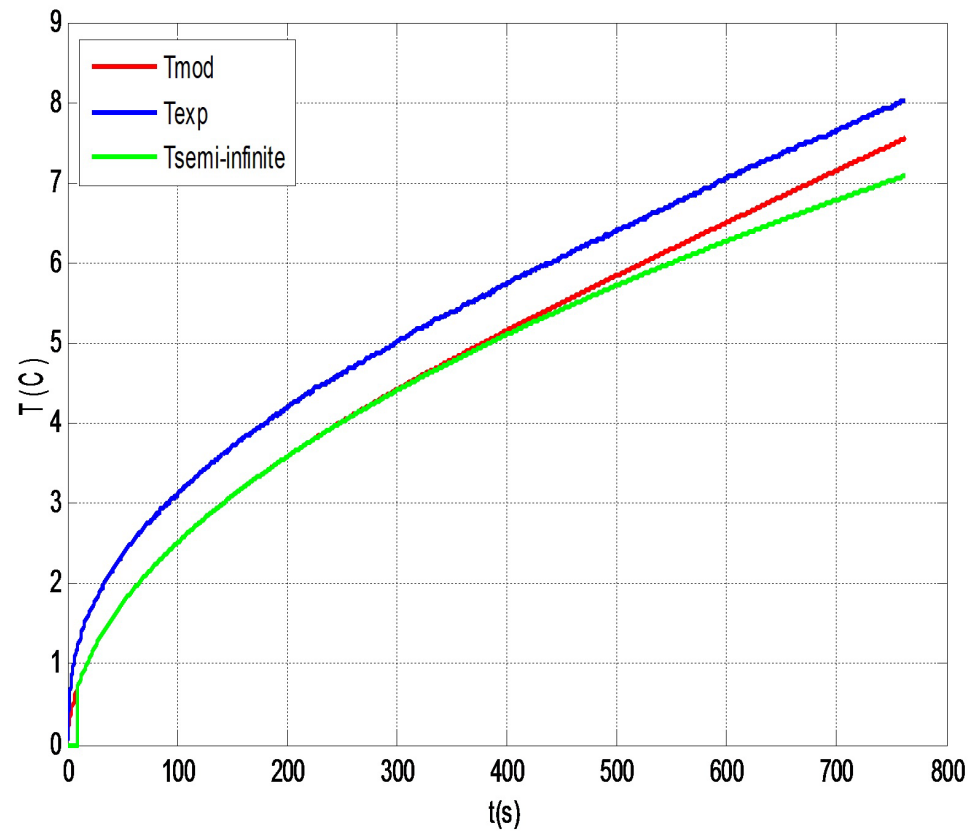

(a)

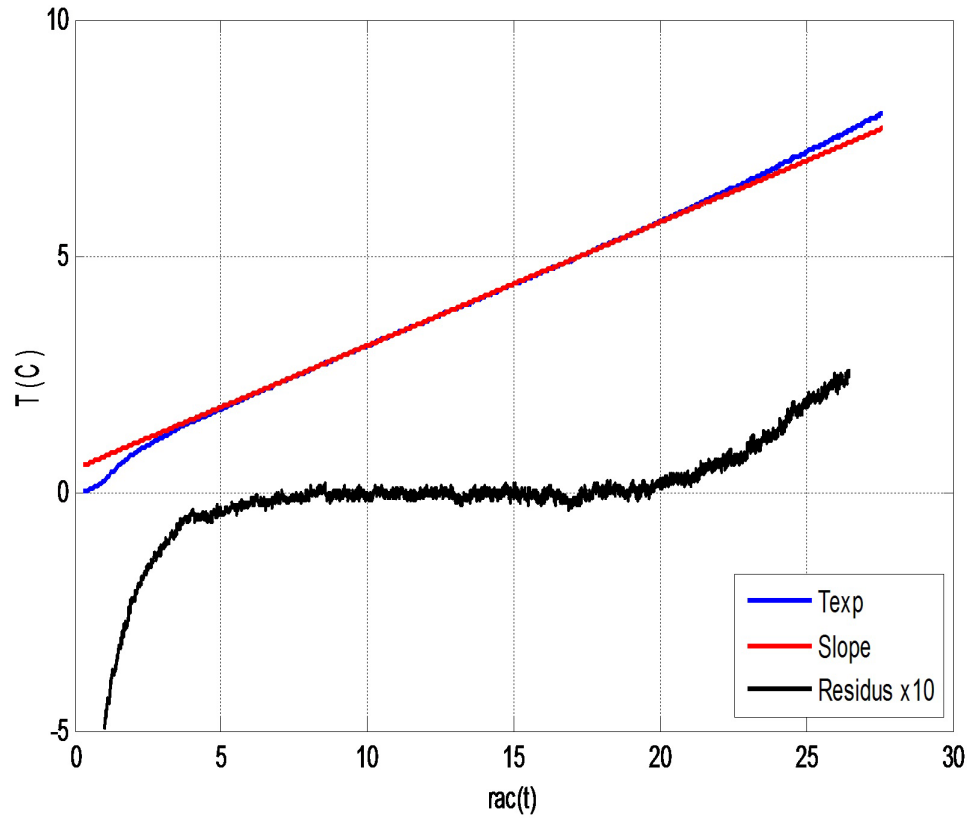

(b)

Figure 13. Temperature curve for sample E3 (a) $T=f(t)$; (b) $T=f(\operatorname{rac}(t))$ with residues curves. 


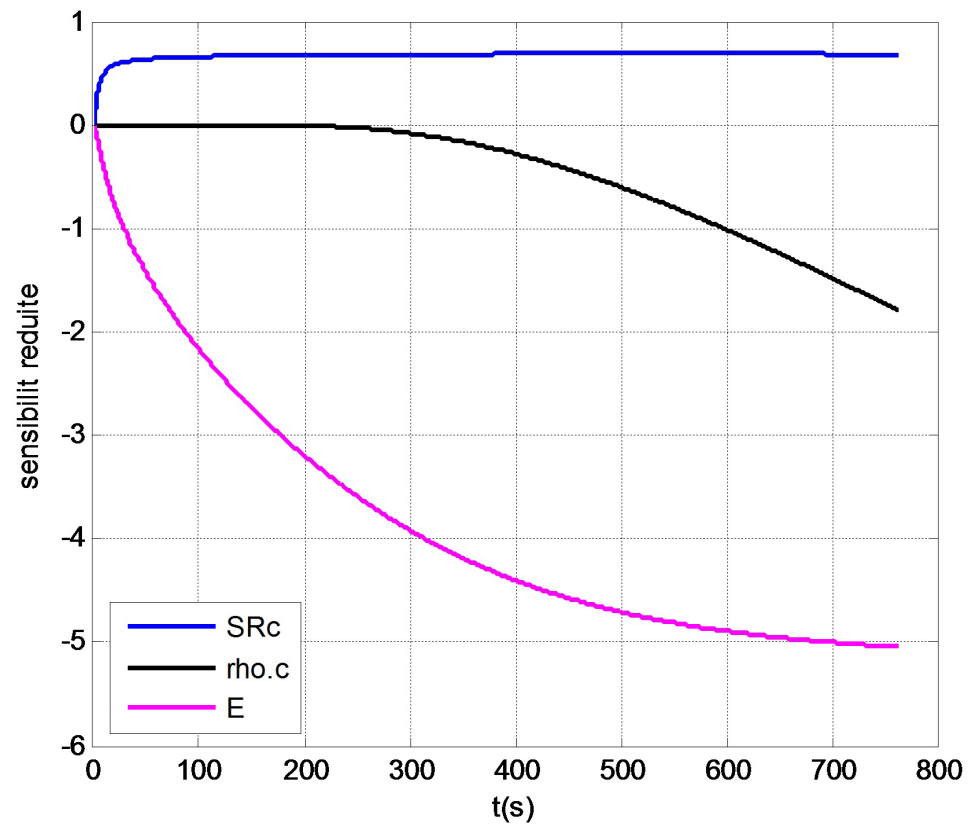

(a)

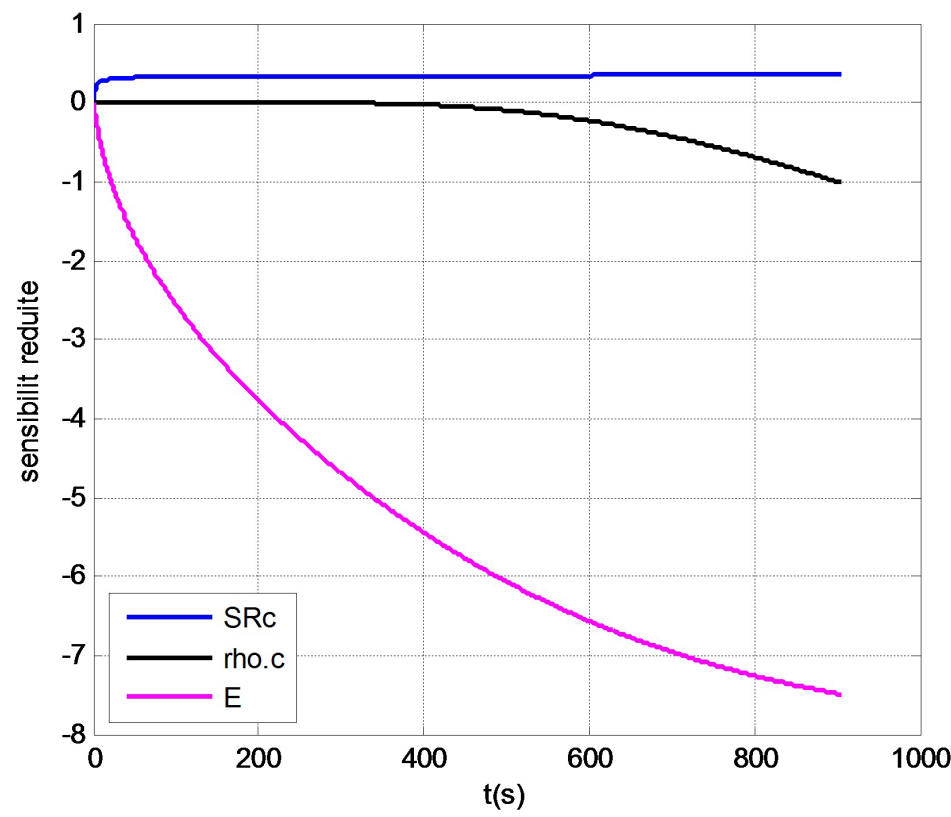

(b)

Figure 14. Reduced sensitivities curves: (a) for samples E0; (b) for samples E3.

- We noticed that the reduced sensitivities of $T$ to the heating sensor becomes constant after $10 \mathrm{~s}$, this shows that the inertia of the heating sensor could be neglected only $10 \mathrm{~s}$ after having measured $T$. This shows that, although the effect of the inertia becomes important as the proportion of fibres in the material increases, the developed model cannot provide a reliable estimate of the thermal contact resistance at the interface of the heat sensor/material.

- Sensitivities of $T$ to $\rho C_{p}$ and to $E$ are decorrelated, but $T$ is sensible to $E$ only 
between 0 and $500 \mathrm{~s}$ and sensible to $\rho C_{p}$ practically after $300 \mathrm{~s}$. The link observed between $\rho C_{p}$ and $R_{i}$ is as a result of strong thermal initial observed 100 $\mathrm{s}$ after having started registering the temperature. This could be fully seen on the residual graph that shows the plotting in Figure 14(b). After having well focused the residual at the centre between $100 \mathrm{~s}$ and $220 \mathrm{~s}$ and the temperature being very sensitive to $E$ within the gap limit (Figure 14(a) and Figure 14(b), a pre-estimate of $E$ was carried out on all the samples within the set interval of $100-220 \mathrm{~s}$. On the contrary $\rho C_{p}$ pre-estimate was done from the moment there was no correlation with $R_{p}$ i.e. between $400 \mathrm{~s}$ and $450 \mathrm{~s}$.

Contrary to the simplified model which does not reduce the sum of quadratic differences (Equation (22)) between the model and the experimental temperature, the completed model instead reduces inversely. We therefore observed a convergence between pre-estimated and experimental results as seen in Figure 15, explaining why the completed model portrays a reliable estimation of the thermophysical parameters $\rho C_{p}$ and $E$.

In a bid to validate and confirm the experimental results with the asymmetric hot plate method, we compared the estimated value of $\left(\rho C_{p}\right)_{e s t}$ with that of $\rho_{\text {app }} \times$ $\left(C_{P}\right)_{D M}$ where the value of $\left(C_{p}\right)_{D M}$ and $p_{a p p}$ are respectively shown in Table 6 and Table 7. We equally compared the value of $\lambda_{\text {est }}$ (Equation (23)) with $\lambda_{\exp }$ as shown by the Equation (32):

$$
\lambda_{\text {exp }}=\frac{E^{2}}{\rho_{a p p} *\left(C_{p}\right)_{D M}}
$$

All the results obtained are shown in Table 8.

When comparing results from both methods which aim at determining the volumetric heat capacity, we can clearly see the mean value of apparent thermal conductivity obtained by the asymmetric hot plate method on one hand and that obtained by the Equation (32), perfectly match (Figure 16). As the use of fibre increases the porosity of composite material, so too decreases the thermal conductivity with the addition of fibres. The results of the experiment showed that blocks $E 4$ have a much lower thermal conductivity than the blocks $E 0$. We came to the conclusion that the use of plant fibres increases the weightlessness of the material without reducing its resistance to compression. This can also mean a reduced thermal conductivity.

Table 8. Results of the thermophysical properties.

\begin{tabular}{|c|c|c|c|c|c|c|c|c|c|}
\hline Ref & $\begin{array}{c}E_{\text {simpl }} l \\
\mathrm{~J} \cdot \mathrm{m}^{-2} \cdot{ }^{\circ} \mathrm{C}^{-1} \cdot \mathrm{s}^{-1 / 2}\end{array}$ & $\begin{array}{c}E_{\text {compl }} \\
\mathrm{J} \cdot \mathrm{m}^{-2} \cdot{ }^{\circ} \mathrm{C}^{-1} \cdot \mathrm{s}^{-1 / 2}\end{array}$ & $\begin{array}{c}(\rho C p)_{\text {est }} \\
\mathrm{J} \cdot \mathrm{m}^{-3} \cdot \mathrm{K}^{-1}\end{array}$ & $\begin{array}{c}\rho_{\text {app }} \times\left(C_{p}\right)_{\mathrm{DM}} \\
\mathrm{J} \cdot \mathrm{m}^{-3} \cdot \mathrm{K}^{-1}\end{array}$ & $\begin{array}{c}\lambda_{\text {est }} \\
\mathrm{W} \cdot \mathrm{m}^{-1} \cdot \mathrm{K}^{-1}\end{array}$ & $\begin{array}{c}\lambda_{\exp } \\
\mathrm{W} \cdot \mathrm{m}^{-1} \cdot \mathrm{K}^{-1}\end{array}$ & $\begin{array}{l}D_{E} \\
\%\end{array}$ & $\begin{array}{c}D_{\rho C} \\
\%\end{array}$ & $\begin{array}{l}D_{\lambda} \\
\%\end{array}$ \\
\hline$E 0$ & 1051.93 & 1046.74 & $1.59210^{6}$ & $1.54510^{6}$ & 0.689 & 0.710 & 0.39 & 2.91 & 2.91 \\
\hline$E 1$ & 995.81 & 994.90 & $1.54610^{6}$ & $1.53910^{6}$ & 0.639 & 0.642 & 0.39 & 0.45 & 0.45 \\
\hline$E 2$ & 912.74 & 913.95 & $1.51810^{6}$ & $1.51910^{6}$ & 0.550 & 0.549 & 0.09 & 0.05 & 0.05 \\
\hline$E 3$ & 878.34 & 876.99 & $1.50510^{6}$ & $1.51210^{6}$ & 0.510 & 0.511 & 0.13 & 0.05 & 0.05 \\
\hline$E 4$ & 853.34 & 851.80 & $1.51110^{6}$ & $1.49510^{6}$ & 0.483 & 0.485 & 0.18 & 1.05 & 0.41 \\
\hline
\end{tabular}

Simpl: simplified model; compl: completed model; est: estimated; exp: experimental; D: standard deviation. 


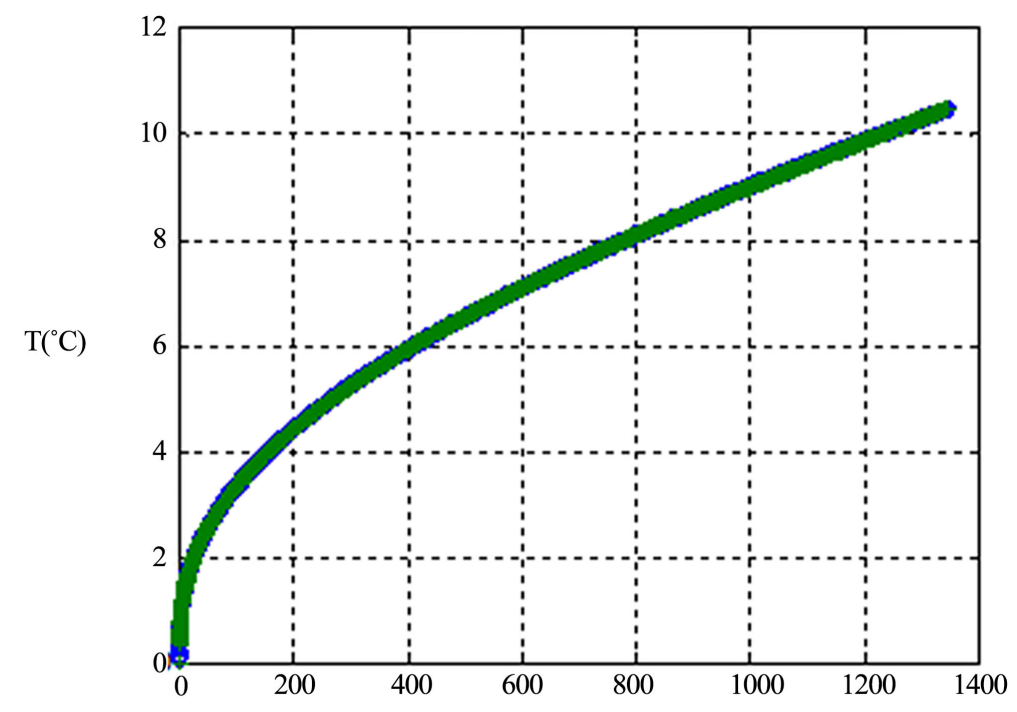

$\mathrm{t}(\mathrm{s})$

Figure 15. Results mixture with the complete model for the $E 4$ sample.

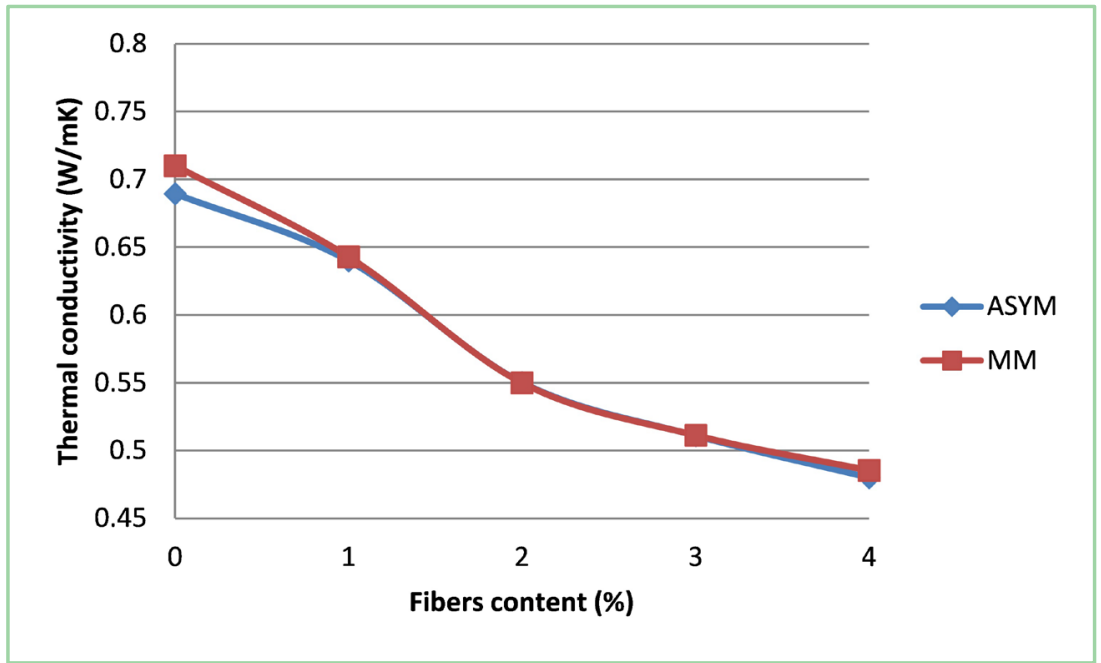

Figure 16. Thermal conductivity of materials according to the fibrous content (ASYM: obtained from Equation (23); DM: obtained with Equation (32)).

\section{Conclusion}

This research work sets out to investigate the energetic and mechanical reinforcement of sun-dried bricks made with laterite and different proportions of thatch fibres from the Meiganga locality of the Adamawa region in Cameroon. Mechanical characterisation studies have shown that with up to $4 \%$ fibre incorporated, the composite materials produced have a very good compressive and flexural strength that meets civil engineering standards. The asymmetric hot plate method used to calculate the thermophysical parametres of these different materials was validated with another method, i.e. the dehydration method, used for determining the heat capacity. With the use of apparent thermal conductivity study, we came to the conclusion that with fibres used, a better thermal insulat- 
ing composite material was the bi-product. These materials can then contribute to ensuring a better thermal comfort of the interior of a building. The extremely hot climate of this region gives credence to the treatment and use of plant fibres to make sun-dried bricks. These could be used to reduce energy consumption thus, limiting the emission of greenhouse gas (especially $\mathrm{CO}_{2}$ ) when air-conditioners are used.

\section{Conflicts of Interest}

The authors declare no conflicts of interest regarding the publication of this paper.

\section{References}

[1] Olivier, J.G.J., Schure, K. and Peters, J. (2017) Trends in Global $\mathrm{CO}_{2}$ and Total Greenhouse Gas Emissions. Summary of 2017 Report. PBL Netherlands Environmental Assessment Agency.

[2] Meggers, F., Leibundgut, H., Kennedy, S., Qind, M., Schlaiche, M., Sobekf, W. and Shukuyag, M. (2012) Reduce $\mathrm{CO}_{2}$ from Buildings With Technology to Zero Emissions. Sustainable Cities and Society, 2, 29-36. https://doi.org/10.1016/j.scs.2011.10.001

[3] Osseni, S.O.G, Apovo, B.D., Ahouannou, C., Sany E.A. and Jannot, Y. (2016) Caractérisation thermique des mortiers de ciment dopés en fibres de coco par la méthode du plan chaud asymétrique à une mesure de température. Afrique Science, $12,119-129$

[4] Meukam, P., Noumowe, A., Jannot Y. and Duval, R. (2003) Caractérisation thermophysique et mécanique des briques de terre stabilisées en vue de l'isolation thermique de bâtiment. Materials and Structures, 36, 453-446. https://doi.org/10.1007/BF02481525

[5] Lamkharouet, N., Boussaid, S., Ezbakhe, H., EL Bakkouri, A., Ajzoul, T. and El Bouard, A. (2001) Etude thermique de la terre de Larache stabilisée au Ciment. Laboratoire de Thermique, Energie solaire \& Environnement, Faculté des Sciences, Université Abdelmalek Essaâdi, Tétouan, 541-546.

[6] Bal, H., Jannot, Y., Gaye, S. and Demeurie, F. (2013) Measurement and Modelisation of the Thermal Conductivity of a Wet Composite Porous Medium: Laterite Based Bricks with Millet Waste Additive. Construction and Building Materials, 41, 586-593. https://doi.org/10.1016/j.conbuildmat.2012.12.032

[7] Meukam, P., Jannot, Y., Noumowe, A. and Kofane, T.C. (2004) Thermophysical Characteristics of Economical Building Materials. Construction and Building Materials, 18, 437-443. https://doi.org/10.1016/j.conbuildmat.2004.03.010

[8] Damfeu, J.C., Meukam, P. and Jannot, Y. (2016) Modeling and Measuring of the Thermal Properties of Insulating Vegetable Fibers by the Asymmetrical Hot Plate Method and the Radial Flux Method: Kapok, Coconut, Groundnut Shell Fiber and Rattan. Thermochimica Acta, 630, 64-77. https://doi.org/10.1016/j.tca.2016.02.007

[9] Damfeu, J.C., Meukam, P., Jannot, Y. and Wati, E.(2017) Modelling and Experimental Determination of Thermal Properties of Local Wet Building Materials. Energy and Buildings, 135, 109-118. https://doi.org/10.1016/j.enbuild.2016.11.022

[10] Elhamdouni, Y., Khabbazi, A., Benayad, C., Mounir, S. and Dadi, A. (2017) Ther- 
mophysical and Mechanical Characterization of Clay Bricks Reinforced by Alfa or Straw Fibers. IOP Conference Series. Materials Science and Engineering, Vol. 186, Beijing, 12-35.

[11] Houben, H. (2009) Blocs de Terre Comprimé: Normes. CDI, Philadelphia.

[12] Elimbi, A. (2005) MIPROMALO: Protocoles d'analyses des matières premières et des produits finis au laboratoire.

[13] MINTP (2009) Séminaire de renforcement des capacités des contrôleurs du Ministère des Travaux Publiques aux techniques de contrôle de qualité des constructions en BTC. Yaounde.

[14] Petkova, R. and Zlatev, P. (2017) Thermal Insulating Properties of Straw Filled Environmentally Friendly Building Materials. Vol. 13, 52-57.

[15] Azhary El, K., Chihab, Y., Mansour, M., Laaroussi, N. and Garoum, M. (2017) Energy Efficiency and Thermal Properties of the Composite Material Clay-Straw. Energy Procedia, 141, 160-164. https://doi.org/10.1016/j.egypro.2017.11.030

[16] Kossi, I.B., Florent, P.K. and Ouedraogo, E. (2014) Thermal and Mechanical Study of the Adobe Stabilized with Straws and/or Cement at Different Rate. International Journal of Engineering and Innovative Technology, 4.

[17] Maillet, D., Andre, S., Batsale, J.C., Degiovanni, A. and Moyne, C. (2000) Thermal Quadrupoles. Wiley, New York.

[18] De Hoog, F.R. and Stokes, A.N. (1982) A Improved Method for Numerical Inversion of Laplace Transforms. SIAM Journal on Scientific and Statistical Computing, 3, 357-366. https://doi.org/10.1137/0903022

[19] Gill, P.E. and Murray, W. (1978) Algorithms for the Solution of the Nonlinear Least-Squares Problems. Journal of Numerical Analysis, 15, 977-992.

[20] Bories, S. and Prantt, M. (1995) Transferts de chaleur dans les milieux poreux. Tech. Ing., B8 (250). 


\section{Nomenclature}

T. Temperature $\left({ }^{\circ} \mathrm{C}\right)$

$E$. Thermal effusivity $\left(\mathrm{J} \cdot \mathrm{m}^{-2} \cdot \mathrm{C}^{-1} \cdot \mathrm{s}^{-1 / 2}\right)$

$\lambda$. Thermal conductivity $\left(\mathrm{W} \cdot \mathrm{m}^{-1} \cdot \mathrm{K}^{-1}\right)$

h. Convective heat loss coefficient $\left(\mathrm{W} \cdot \mathrm{m}^{-2} \cdot{ }^{\circ} \mathrm{C}^{-1}\right)$

$R$. Thermal contact resistance $\left({ }^{\circ} \mathrm{C}^{-1} \cdot \mathrm{W}^{-1}\right)$

$C_{p}$. Heat capacity $\left(\mathrm{J} \cdot \mathrm{kg}^{-1} \cdot \mathrm{K}^{-1}\right)$

$\rho$. Density $\left(\mathrm{kg} \cdot \mathrm{m}^{-3}\right)$

$e$. Thickness (m)

$\theta$. Laplace transform of temperature

$P$. Laplace parameter

$\Phi$. Laplace transform of heat flux

$\varphi_{0}$. Heat flux density $\left(\mathrm{W} \cdot \mathrm{m}^{-2}\right)$

$\rho C_{p}$. Volumetric heat capacity $\left(\mathrm{J} \cdot \mathrm{m}^{-3} \cdot \mathrm{K}^{-1}\right)$

\section{Subscripts}

$P_{0}$. Insulating blocks

s. Sample

comp. Completed model

simpl. Simplified model

h. Heation element

exp. Experimental

Pre. Pre-estimated

DM. Dehydration Method

Sinf. Semi-infinite medium

c. Center 